\title{
Study on Critical Hydraulic Gradient Theory of Flow Soil Failure in Cohesive Soil Foundation
}

\author{
Mei Zhou $\mathbb{D}^{D}$, Faning Dang $\mathbb{D}^{D}$, Yutao Li, Jiulong Ding, and Jun Gao \\ Institute of Geotechnical Engineering, Xi'an University of Technology, Xi'an, Shaanxi 710048, China \\ Correspondence should be addressed to Faning Dang; dangfn@163.com
}

Received 26 February 2021; Revised 21 April 2021; Accepted 20 May 2021; Published 2 June 2021

Academic Editor: Chuangzhou Wu

Copyright (c) 2021 Mei Zhou et al. This is an open access article distributed under the Creative Commons Attribution License, which permits unrestricted use, distribution, and reproduction in any medium, provided the original work is properly cited.

\begin{abstract}
The current formula of critical hydraulic gradient is not adapted to solve critical hydraulic gradient of cohesive soil. Assume that the seepage failure mode of the cohesive soil foundation was cylindrical or inverted circular truncated cone, based on the calculation formula of the critical hydraulic gradient of Terzaghi, the analytical formula of the critical hydraulic gradient considering the influence of the shear strength of the soil was derived. Then, the seepage failure process of the clay layer was simulated numerically, and the effects of the clay layer thickness, failure radius, and shear strength indexes on the critical hydraulic slope were analyzed. The comparison results show that the numerical test results are in good agreement with the calculated results of the new formula. In addition, the critical hydraulic gradient of sandy loam and loess under different working conditions was studied severally by a self-made permeation failure instrument. The results show that the critical hydraulic gradient decreases with the increase of soil thickness and failure radius, and the maximum error between the test and the corresponding formula results is no more than $16 \%$.
\end{abstract}

\section{Introduction}

Infiltration is one of the important factors of engineering accidents such as dams and foundation pits, which can drive people to deeply explore the characteristics of seepage failure for better prevention and control of the occurrence of engineering accidents $[1,2]$. According to the investigation, it is found that a lot of researches on the critical conditions of soil seepage failure have been conducted and hence some useful conclusions have been obtained. For example, $W u$ et al. used biogrouting and other methods to analyze the permeability characteristics of soil and coal mass [3-6]. Zhang et al. developed a new fluid-solid coupled numerical approach by combining the dynamic fluid mesh (DFM) method with the DEM, which can be applied to analyze the seepage mechanism of soil; in addition, the stress-strain behavior for soil subjected to internal erosion was studied by threedimensional DEM modeling [7-10]. The crack direction of the soil during the infiltration process is an important factor affecting the seepage failure. Rabczuk and Belytschko proposed a model that can be used to simulate soil crack propagation $[11,12]$. A famous formula was proposed by Terzaghi for calculating the critical hydraulic gradient according to the balance principle of self-gravity, hydrostatic buoyancy, and seepage force of soil particles in water [13]. Changxi considered the influence of the shape resistance of soil particles [2] to the critical hydraulic gradient based on the former theory. Israr and Indraratna obtained a calculation method of hydraulic gradient considering the friction between particles in the soil by introducing a stress reduction coefficient [14, 15]. The soil effective stress and the stress reduction of fine particles were combined by Wang et al. who put forward a formula for calculating critical hydraulic gradient of fine particles in sandy soil [16]. Jiang equated the pores of clay into circular pipes with uniform distribution and subsequently analyzed the critical condition of seepage failure of clay from the perspective of pipe flow, and finally, the mathematical relationship between the pore diameter and the critical condition was established [17]. $W u$ and Gao established the calculation formula of critical hydraulic gradient in case where piping happened, based on the particle gradation curve and porosity of the soil [18]. The empirical formula of critical hydraulic gradient of piping, which was expressed via confining pressure $[19,20]$, was performed by Luo et al. The whole 
process from occurrence to failure of the soil flow was reproduced by Tang et al., using the similar model [21]. Based on seepage test, the low and high critical hydraulic gradients corresponding to the local flow and global loss of fine particles were defined by Liang et al. [22]. Yang et al. studied the influence of stress state on the critical hydraulic gradient and permeability coefficient of soil through indoor tests [23-25].

It is well known that critical hydraulic slope is an important basis to judge whether seepage failure will occur in soil. Therefore, it is an inevitable topic to study critical hydraulic slope. Although there are many theoretical formulas for the critical condition of seepage failure, however, there is no unified method so far to calculate the critical hydraulic gradient, when the flow soil failure phenomenon of the clay foundation occurs. In view of this situation, this paper considers the effect of clay shear strength; based on the existing theoretical results, the formula which can calculate the critical hydraulic gradient of cohesive soil foundation when the flow soil occurrence is derived, and its rationality is verified by a series of numerical experiments and laboratory tests.

\section{Establish an Analytical Formula for Critical Hydraulic Gradient of Cohesive Soil Foundation}

At present, the Terzaghi formula is often used to calculate the critical hydraulic slope for seepage failure of foundation, which is given by

$$
i_{\mathrm{cr}}=\frac{\gamma^{\prime}}{\gamma_{w}}=(1-n)\left(G_{s}-1\right)
$$

where $i_{\text {cr }}$ is the critical hydraulic gradient, $G_{s}$ is the relative density of soil particles, and $n$ is the porosity.

It is evident that Eq. (1) neglects the influence of friction resistance between soil particles when calculating the critical hydraulic gradient [26], while the critical hydraulic gradient of cohesive soil foundation is bound up with its shear strength, and therefore, this formula falls into a failure to solve the critical hydraulic gradient of cohesive soil foundation. As a result of this factor that we just have analyzed, the following study is going to take into account the effects of cohesive soil shear strength and to modify the formula of critical hydraulic gradient.

Assuming that there is a double-layer building foundation, the upper and lower layers are cohesive soil layer and sand gravel layer, respectively, in which there is weak area in the clay layer, as shown in Figure 1(a). Besides, the water head difference between the top and bottom of the clay layer is $\Delta h$, the seepage failure will occur in the weak area of the clay layer as soon as $\Delta h$ exceeds a certain critical value. This paper assumes that the failure mode of flow soil in cohesive soil foundation is (b) or (c) in Figure 1.

2.1. Cylinder Failure Mode. Take the cylinder with radius $r$ and clay layer thickness $h$ as the soil separation body to analyze its stress state, as shown in Figure 1(b). It is easy to see that the cylinder subjects to upward seepage force and downward effective gravity, and the separation body will trend to move upward when the former is greater than the latter. At the same time, there is a downward shear force on the boundary of the separation body. According to the equilibrium condition of the force, the following formula can be obtained.

$$
J=G+\tau
$$

where $J, G$, and $\tau$ are the total seepage force, effective gravity of soil, and shear force between the separated body and the surrounding soil, respectively. $J$ and $G$ can be represented as follows:

$$
\begin{aligned}
& J=j \bullet V=i \gamma_{w} \bullet \pi r^{2} h, \\
& G=\gamma \bullet \pi r^{2} h .
\end{aligned}
$$

Theoretically, when the shear force is equal to the shear strength of the soil multiplied by the area of the shear surface, the hydraulic gradient in Eq. (2) is the critical hydraulic gradient for seepage failure of the clay foundation, i.e., the shear force of soil in critical state is given by

$$
\tau=(c+\sigma \tan \varphi) \cdot 2 \pi r h
$$

Substituting Eqs. (3)-(5) into Eq. (2), the latter is written as

$$
i_{\mathrm{cr}} \gamma_{w} \bullet \pi r^{2} h=\gamma \cdot \pi r^{2} h+(c+\sigma \tan \varphi) \cdot 2 \pi r h
$$

Eq. (7) can be acquired by moving the term and simplifying of Eq. (6):

$$
i_{\alpha}=\frac{\gamma}{\gamma_{w}}+\frac{2(c+\sigma \tan \varphi)}{\gamma_{w} \cdot r}
$$

where $\sigma$ is the average normal stress on the failure surface, since the failure surface is vertical, and the average normal stress is theoretically equal to the average static earth pressure, which is expressed by Eq. (8).

$$
\sigma=\frac{1}{2} \gamma^{\prime} h K_{0}
$$

The critical hydraulic gradient calculation formula of the cohesive soil foundation when the failure mode is a cylinder can be obtained by substituting Eq. (8) into Eq. (7), which is written as

$$
i_{\mathrm{cr}}=\frac{\gamma}{\gamma_{w}}+\frac{2\left(c+1 / 2 \gamma^{\prime} h K_{0} \tan \varphi\right)}{\gamma_{w} \bullet r},
$$

where $\gamma_{w}$ is the weight of water, equaling to $9.8 \mathrm{kN} / \mathrm{m}^{3} ; \gamma^{\prime}$ is the effective unit weight of soil, $\mathrm{kN} / \mathrm{m}^{3} ; c$ is the cohesion, 


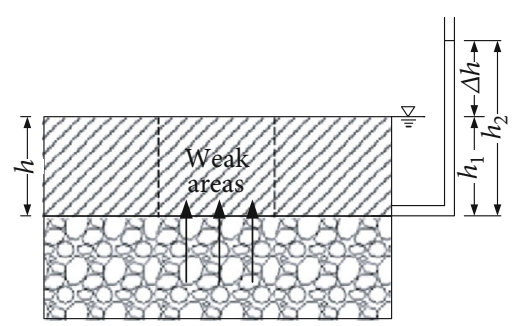

(a) Clay layer under the effect of water head difference

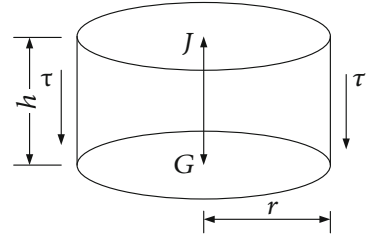

(b) Cylinder failure mode

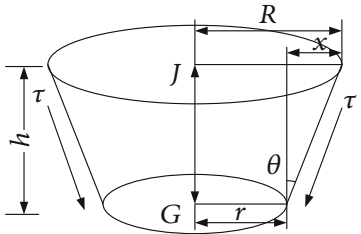

(c) Inverted frustum of a cone failure mode

FIGURE 1: Schematic diagram of seepage failure of clay layer.

$\mathrm{kPa} ; \varphi$ is the internal friction angle, ${ }^{\circ} ; K_{0}$ is the lateral pressure coefficient of soil, which is calculated by $K_{0}=1-\sin \varphi$.

2.2. Inverted Frustum of a Cone Failure Mode. Supposing the radius of the upper and lower surfaces of the separation body of the inverted frustum of a cone is $R$ and $r$, respectively, the thickness of the clay layer is $h$, and the angle between the generatrix and the axis is $\theta$, as shown in Figure 1(c). According to the equilibrium conditions of gravity, seepage force, and vertical component of shear force on the boundary surface, the results are as follows:

$$
\begin{gathered}
J=G+\tau \cos \theta, \\
i_{\mathrm{cr}} \gamma_{w} V=\gamma V+(c+\sigma \tan \varphi) A \cos \theta,
\end{gathered}
$$

where $V$ and $A$ are the volume and side area of the inverted frustum of a cone, respectively.

It can be seen from Figure 1(c) that the radius difference between the upper and lower surfaces of the inverted frustum of a cone is $x(x=h \tan \theta)$, the relationship between the $R$ and $r$ is expressed as $R=r+h \tan \theta$, and the length of the busbar is $l\left(l=\sqrt{h^{2}+(R-r)^{2}}=h \sqrt{1+\tan ^{2} \theta}\right)$.

The expressions of the side area and volume of the inverted frustum of a cone are as follows:

$$
\begin{gathered}
A=\pi l(R+r)=\pi h \sqrt{1+\tan ^{2} \theta}(r+h \tan \theta+r) \\
=\pi h \sqrt{1+\tan ^{2} \theta}(2 r+h \tan \theta), \\
V=\frac{\pi h}{3}\left(R^{2}+r^{2}+R r\right)=\frac{\pi h}{3}\left[3 r^{2}+3 r h \tan \theta+h^{2} \tan ^{2} \theta\right] .
\end{gathered}
$$

Substituting Eq. (12) and Eq. (13) into Eq. (11) and then simplifying related items, Eq. (11) can be expressed as follows:

$$
\begin{aligned}
i_{\mathrm{cr}}= & \frac{\gamma}{\gamma_{w}}+\frac{(c+\sigma \tan \varphi)}{\gamma_{w}} \cdot \frac{A \cos \theta}{V}=\frac{\gamma}{\gamma_{w}}+\frac{(c+\sigma \tan \varphi)}{\gamma_{w}} \\
& \cdot \frac{\pi h \sqrt{1+\tan ^{2} \theta}(2 r+h \tan \theta) \cos \theta}{\pi h / 3\left[3 r^{2}+3 r h \tan \theta+h^{2} \tan ^{2} \theta\right]} \\
= & \frac{\gamma}{\gamma_{w}}+\frac{3(c+\sigma \tan \varphi)}{\gamma_{w}} \cdot \frac{(2 r+h \tan \theta)}{\left[3 r^{2}+3 r h \tan \theta+h^{2} \tan ^{2} \theta\right]},
\end{aligned}
$$

where $\sigma$ is the average normal stress on the failure surface and can be calculated by Eq. (15).

$$
\sigma=\frac{1}{2} \gamma^{\prime} h K_{0} \cos \theta
$$

When the failure mode is a cylinder, the calculation formula for the critical hydraulic gradient of the cohesive soil foundation will be obtained if we substitute Eq. (15) into Eq. (14), which is written as

$$
\begin{aligned}
i_{\mathrm{cr}}= & \frac{\gamma}{\gamma_{w}}+\frac{3\left(c+1 / 2 \gamma^{\prime} h K_{0} \cos \theta \tan \varphi\right)}{\gamma_{w}} \\
& \cdot \frac{(2 r+h \tan \theta)}{\left[3 r^{2}+3 r h \tan \theta+h^{2} \tan ^{2} \theta\right]} .
\end{aligned}
$$

When $\theta=0^{\circ}$, Eq. (16) is simply reduced to Eq. (9), which indicates sufficiently that Eq. (16) is the most general expression of critical hydraulic gradient for seepage failure of cohesive soil foundation. 


\section{Analysis on Calculation Formula of Critical Hydraulic Gradient of Cohesive Soil Foundation}

It is assumed that the form of flow soil failure in the cohesive soil foundation is an inverted frustum of a cone, and Eq. (16) is a function with five related variables, which is related to clay layer thickness, failure radius, two strength parameters, and stress diffusion angle. Given a basic working condition, that is, the clay layer thickness is $2 \mathrm{~m}$, the failure radius of lower surface of soil layer is $2 \mathrm{~m}$, the cohesion is $25 \mathrm{kPa}$, the internal friction angle and stress diffusion angle are both $20^{\circ}$, and then the influence of these five parameters on the critical hydraulic gradient of cohesive soil foundation is analyzed.

3.1. Influence of Clay Layer Thickness on Critical Hydraulic Gradient of Cohesive Soil Foundation. Taking the thickness of clay layer as a variable, the influence of clay layer thickness on the critical hydraulic gradient is analyzed by comparing the critical hydraulic gradient under two conditions of considering and ignoring the clay layer thickness. The results are shown in Figure 2.

It can be seen from Figure 2 that the critical hydraulic gradient would decrease in proportion to the clay layer thickness when considering the influence of clay layer thickness on the critical hydraulic gradient. The smaller the clay layer thickness is, the smaller the critical hydraulic slope difference between the two conditions is. For example, when the failure radius is $2 \mathrm{~m}$, the maximum difference is $8.45 \%$ when the clay layer thickness is less than $2 \mathrm{~m}$; when the clay layer thickness is less than $0.5 \mathrm{~m}$, the maximum difference is only $2.59 \%$; therefore, when the clay layer thickness is relatively thin relative to the range of soil layer, its influence on the critical hydraulic slope of cohesive soil can be ignored. It should be noted that the critical hydraulic gradient and the critical head difference are completely different concepts, and the critical head difference is positively correlated with the clay layer thickness.

3.2. Influence of Failure Radius on Critical Hydraulic Gradient of Cohesive Soil Foundation. The relation curve between the critical hydraulic gradient and the failure radius is shown in Figure 3, from which it can be seen that when the failure radius is small, the critical hydraulic slope decreases rapidly with the increase of the failure radius; with the increase of failure radius, the slope of $i_{\text {cr }} \sim r$ curve decreases, and the critical hydraulic gradient decreases with the increase of failure radius. Generally speaking, the critical hydraulic gradient decreases inversely with the increase of failure radius. In brief, the critical hydraulic gradient decreased as the failure radius increased; the reason is that the larger the failure radius (other conditions being equal), the smaller the constraint effect of cohesion at the boundary of clay layer weak zone on soil mass is, and the lower the head difference needed for soil seepage failure is, thus the smaller the critical hydraulic slope is. When the failure radius is greater than $3 \mathrm{~m}$, several groups of $i_{\mathrm{cr}} \sim r$ curves tend to coincide; when the failure radius is greater than $5 \mathrm{~m}$, the critical hydraulic gradient of cohesive soil tends to a fixed value.

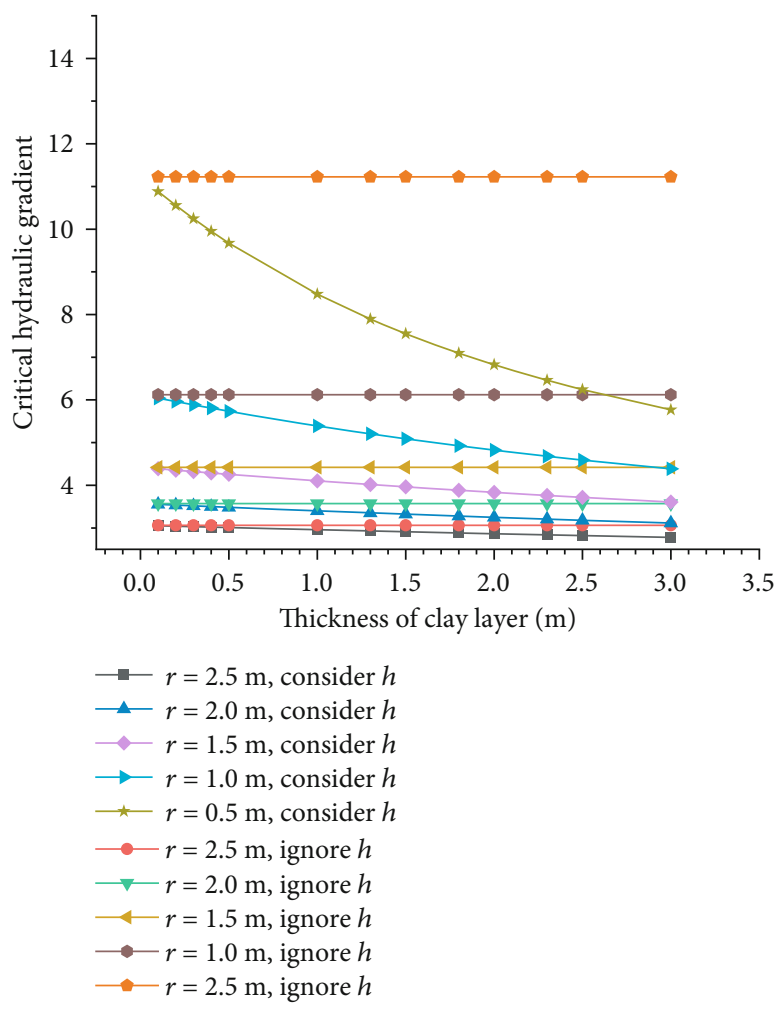

FIgURE 2: The curve between critical hydraulic gradient and thickness of clay layer.

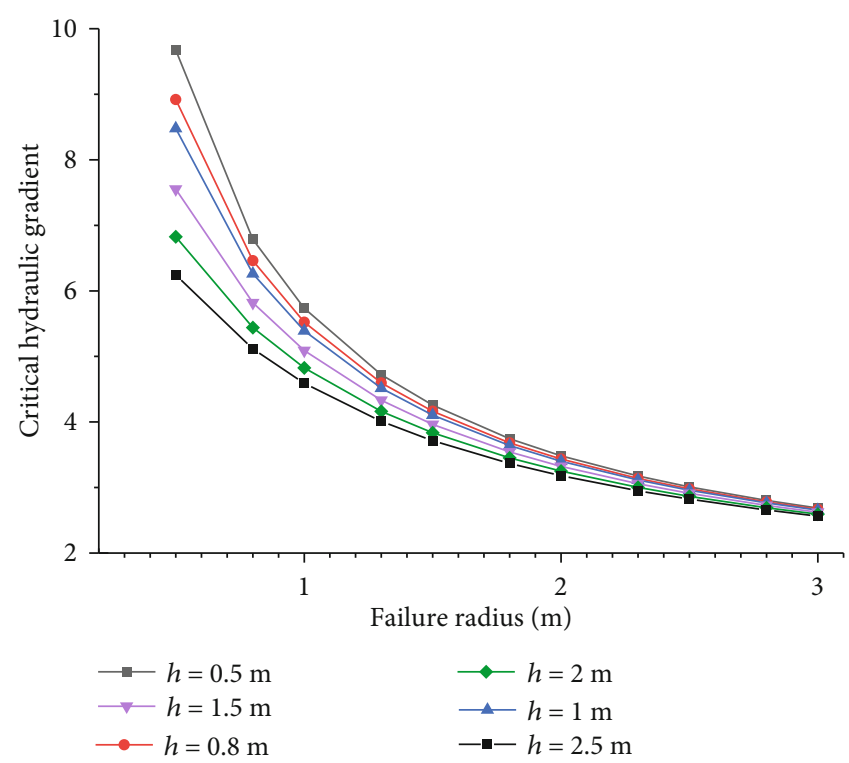

FIGURE 3: The curve between critical hydraulic gradient and failure radius.

To conclude, in the case that the radius of the failure opening is determined, Eq. (16) can be adopted to calculate the critical hydraulic gradient in the actual foundation pit or dam engineering; on the contrary, the hydraulic gradient corresponding to the failure radius of $5 \mathrm{~m}$ is taken as the critical hydraulic gradient. 


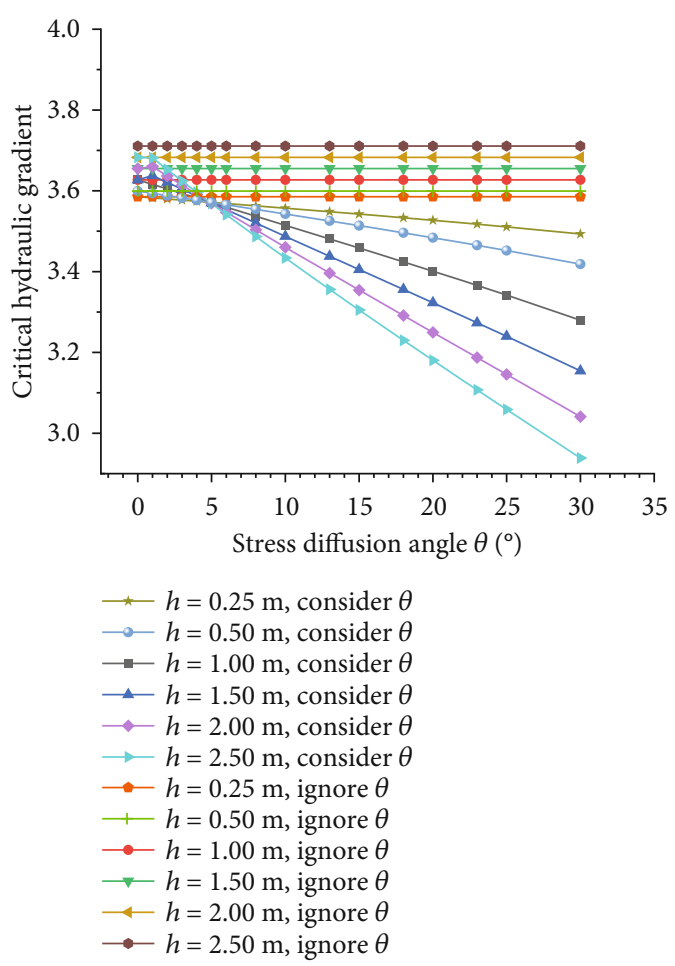

FIGURE 4: The curve between critical hydraulic gradient and angle of stress dispersion.

\subsection{Influence of Stress Diffusion Angle on Critical Hydraulic} Gradient of Cohesive Soil Foundation. It can be seen from Figure 4 that the stress diffusion angle has a certain influence on the critical hydraulic gradient; the critical hydraulic gradient decreases slightly with the increase of the stress diffusion angle. Moreover, the influence of the stress diffusion angle on the critical hydraulic slope is related to the clay layer thickness. The thicker the clay layer, the greater the influence of the stress diffusion angle on the critical hydraulic gradient; on the contrary, the smaller the influence is, the smaller the difference of the critical hydraulic gradient corresponding to considering and ignoring the stress diffusion angle. When $h=0.25 \mathrm{~m}$ and $\theta=0 \sim 30^{\circ}$, the maximum difference is about $4.59 \%$. Generally speaking, the clay layer thickness with flow soil failure is thin, and thus, the influence of stress diffusion angle on the critical hydraulic gradient can be ignored.

\subsection{Influence of Internal Friction Angle on Critical Hydraulic} Gradient of Cohesive Soil Foundation. The relation curve between the critical hydraulic gradient and the internal friction angle is shown in Figure 5, from which it can be seen that the internal friction angle has a certain influence on the critical hydraulic gradient, and the critical hydraulic gradient increases slightly with the increase of internal friction angle. Moreover, the influence of the internal friction angle on the critical hydraulic slope is related to the clay layer thickness; the thicker the clay layer, the greater the influence of the internal friction angle on the critical hydraulic gradient. When $h=2.5 \mathrm{~m}$ and $\varphi=0^{\circ} \sim 30^{\circ}$, the maximum error is $5.16 \%$; when $h=0.5 \mathrm{~m}$ and $\varphi=0^{\circ} \sim 30^{\circ}$, the maximum error is $1.13 \%$. In general, the influence of internal friction angle

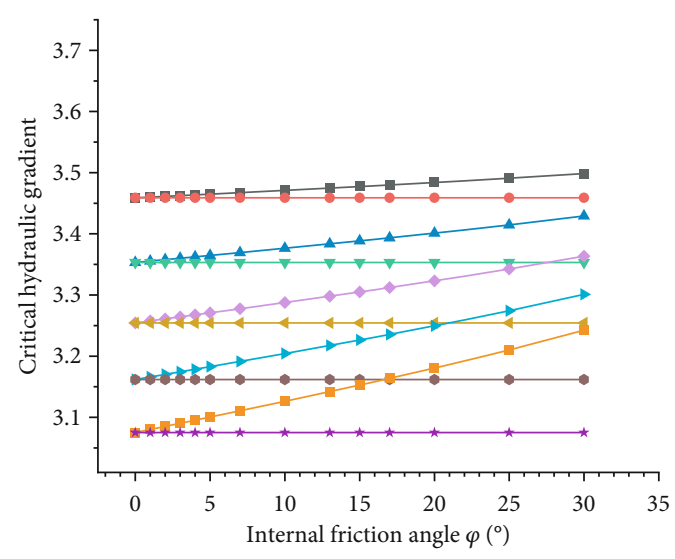

$$
\begin{aligned}
& \longrightarrow h=0.5 \mathrm{~m} \text {, consider } \varphi \\
& \longrightarrow h=2.0 \mathrm{~m} \text {, consider } \varphi \\
& \multimap h=1.5 \mathrm{~m} \text {, consider } \varphi \\
& \longrightarrow h=2.0 \mathrm{~m} \text {, consider } \varphi \\
& -h=2.5 \mathrm{~m} \text {, consider } \varphi \\
& \longrightarrow h=0.5 \mathrm{~m} \text {, ignore } \varphi \\
& \checkmark-h=1.0 \mathrm{~m} \text {, ignore } \varphi \\
& \varangle h=1.5 \mathrm{~m} \text {, ignore } \varphi \\
& \text { - } h=2.0 \mathrm{~m} \text {, ignore } \varphi \\
& \text { * } h=2.5 \mathrm{~m} \text {, ignore } \varphi
\end{aligned}
$$

FIgURE 5: The curve between critical hydraulic gradient and internal friction angle.

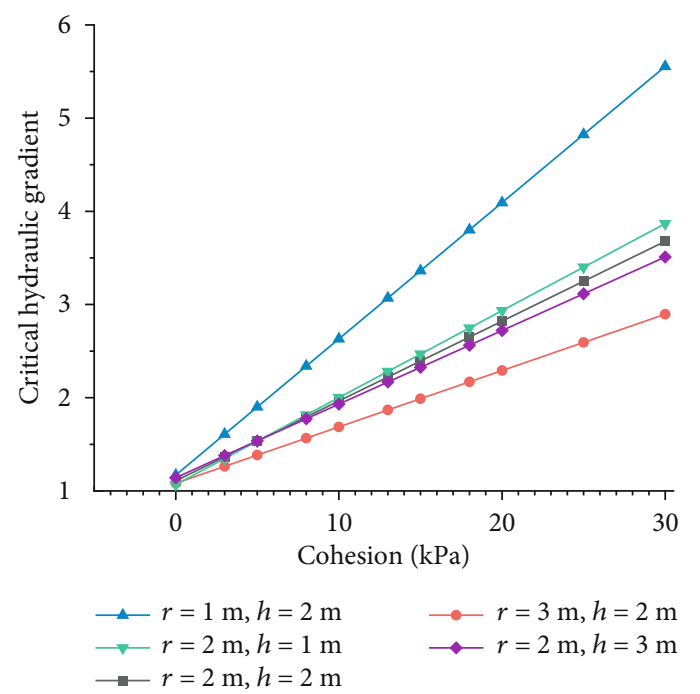

FIgURE 6: The curve between critical hydraulic gradient and cohesion.

on the critical hydraulic gradient of cohesive soil is so weak that it is negligible.

3.5. Influence of Cohesion on Critical Hydraulic Gradient of Cohesive Soil Foundation. The relation curves between the critical hydraulic gradient and cohesion under different working conditions are shown in Figure 6. By comparing the $i_{\mathrm{cr}} \sim c$ relation curves under different working conditions, it can be found that the critical hydraulic gradient increased as the failure radius increased. The reason for this correlation is that the greater the cohesion of the soil (other conditions are the same), the stronger the constraint action of the soil 


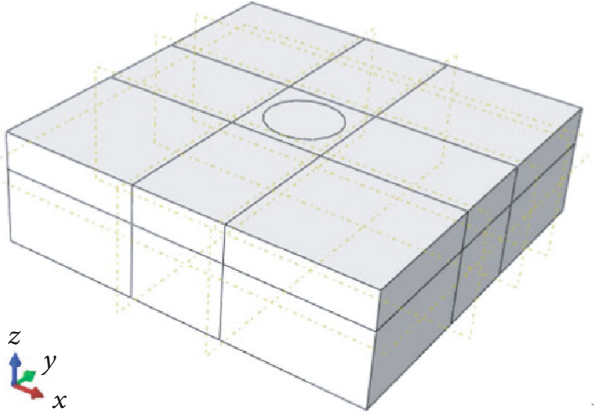

(a) Model diagram

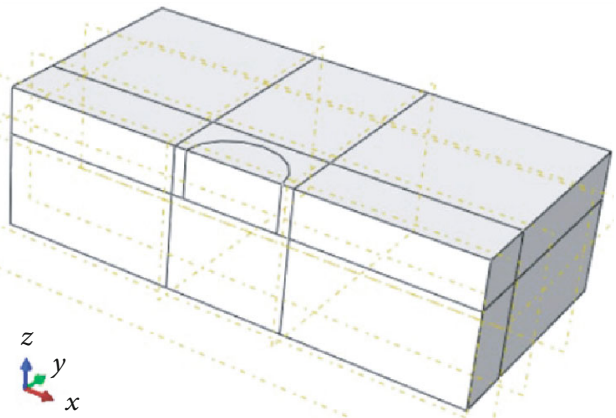

(b) $z-x$ section at half-length along the $y$-axis of the model

Figure 7: Schematic diagram of finite element model.

is, and the greater the head difference is required for the clay layer to permeate, thus the greater the critical hydraulic slope is. Moreover, it is obvious that there is a great difference between the critical hydraulic slope under the conditions of considering cohesion and ignoring cohesion. For example, " $h=2 \mathrm{~m}, r=2 \mathrm{~m}, c=5 \mathrm{kPa}$," the critical hydraulic gradient considering cohesion is 1.54 , and the critical hydraulic gradient ignoring cohesion is 1.11 , and the difference between them is as high as $27.9 \%$. This shows that if the critical hydraulic gradient formula of noncohesive soil is used to calculate the critical hydraulic gradient of cohesive soil foundation, it is necessary to consider the influence of cohesion on the critical hydraulic gradient; it is shown that there is a big error in calculating the critical hydraulic gradient of cohesive soil foundation by using the formula of critical hydraulic gradient of noncohesive soil, which further indicates that it is necessary to consider the influence of cohesion on the critical hydraulic gradient.

3.6. Further Discussion on the Formula of Critical Hydraulic Gradient of Cohesive Soil Foundation. The failure mode of the inverted frustum of a cone of the clay foundation is similar to the punching failure of the inverted foundation, and the value of $\theta$ can be determined by imitating the calculation method of the stress diffusion angle in the foundation treatment. When the buried depth of foundation $(H)$ is equal to zero, the stress begins to diffuse from the bottom of the foundation; when the $H$ is greater than zero, the stress begins to diffuse from the $H / 3$ above the bottom of the foundation, and the variation range of the stress diffusion angle is approximately equal to the internal friction angle of the soil [27]. It can be considered as the foundation model which the buried depth is zero to exam, when the upward seepage force acts on the bottom of the weak zone of the clay layer, and the seepage force begins to spread upward from the bottom of the clay layer. The $\theta$ is stress diffusion angle which can be normally defined as clay's internal friction angle $\varphi$, viz., $\theta=\varphi$.

In general, the internal friction angle of saturated soft clay is pretty small [28], which usually can be ignored in engineering practices; in addition, the thickness of the viscous soil layer is generally less than $1 \mathrm{~m}$, when there is an occurrence of flow soil failure, if $\varphi=0 \sim 10^{\circ}$, so $K_{0} \cos \theta \tan \varphi=0 \sim$ 0.14 , and the error between the calculation results of consid-
TABle 1: Model parameter table.

\begin{tabular}{lcccc}
\hline Material type & $\begin{array}{c}E \\
\mathrm{MPa}\end{array}$ & $\begin{array}{c}k \\
\mathrm{~cm} / \mathrm{s}\end{array}$ & $e$ & $\begin{array}{c}\rho_{\text {sat }} \\
\mathrm{g} / \mathrm{cm}^{3}\end{array}$ \\
\hline Clay layer & 20 & $5 e-8$ & 0.75 & 2.0 \\
Weak clay area & 18 & $1 e-7$ & 0.85 & 1.95 \\
Gravel layer & 45 & $5 e-3$ & 0.55 & 2.05 \\
\hline
\end{tabular}

ering $\varphi$ or not is no more than 5\%, and hence, Eq. (16) can be simplified into the following equation.

$$
i_{\mathrm{cr}}=\frac{\gamma}{\gamma_{w}}+\frac{2 c}{\gamma_{w} \cdot r} .
$$

\section{Numerical Test Verification on Rationality of Analytical Formula for Critical Hydraulic Gradient of Cohesive Soil Foundation}

In this part, the seepage failure process of the viscous soil layer is simulated by finite element software, and the influences of the thickness of the clay layer, the radius of the weak zone of the clay layer, the cohesion, and the angle of internal friction on the critical hydraulic slope are analyzed. The results of the numerical simulation and Eq. (16) are compared to verify the rationality of the new formula in this paper.

The size of the numerical model is $20 \times 20 \times 6 \mathrm{~m}$, as shown in Figure 7(a), in which the upper and lower layers are clay layer $(2 \mathrm{~m})$ and sand and gravel layer $(4 \mathrm{~m})$, respectively. Moreover, a cylindrical weak area with radius of $2 \mathrm{~m}$ is set in the center of clay layer, and the model parameters are shown in Table 1. The elastic-plastic constitutive model and Mohr-Coulomb criterion are adopted in the calculation. The model has a total of 28288 nodes and 31467 elements, and the element type is C3D20RP. In addition, the lateral boundary of the model is constrained by normal direction, the top pore pressure is set to zero, and the bottom is fully constrained and applied.

According to the direct tensile test results of clay in reference [29], the peak tensile strain of clay with a moisture content of $14 \% \sim 17 \%$ is about $0.15 \% \sim 0.34 \%$. Combined with the research results of relevant literature and a large number of 


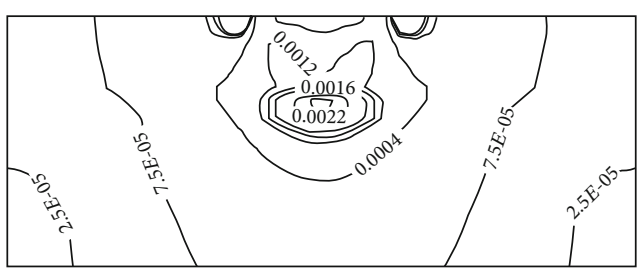

(a) Strain

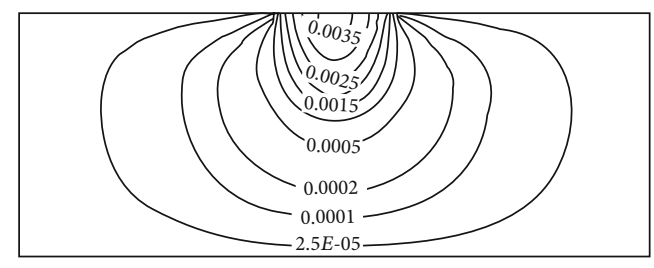

(b) Vertical displacement (m)

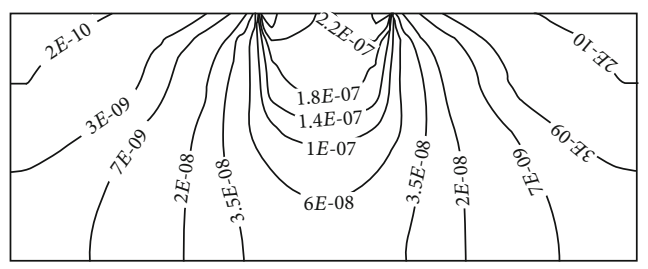

(c) Flow velocity $(\mathrm{m} / \mathrm{s})$

FIGURE 8: Seepage failure contour cloud map.
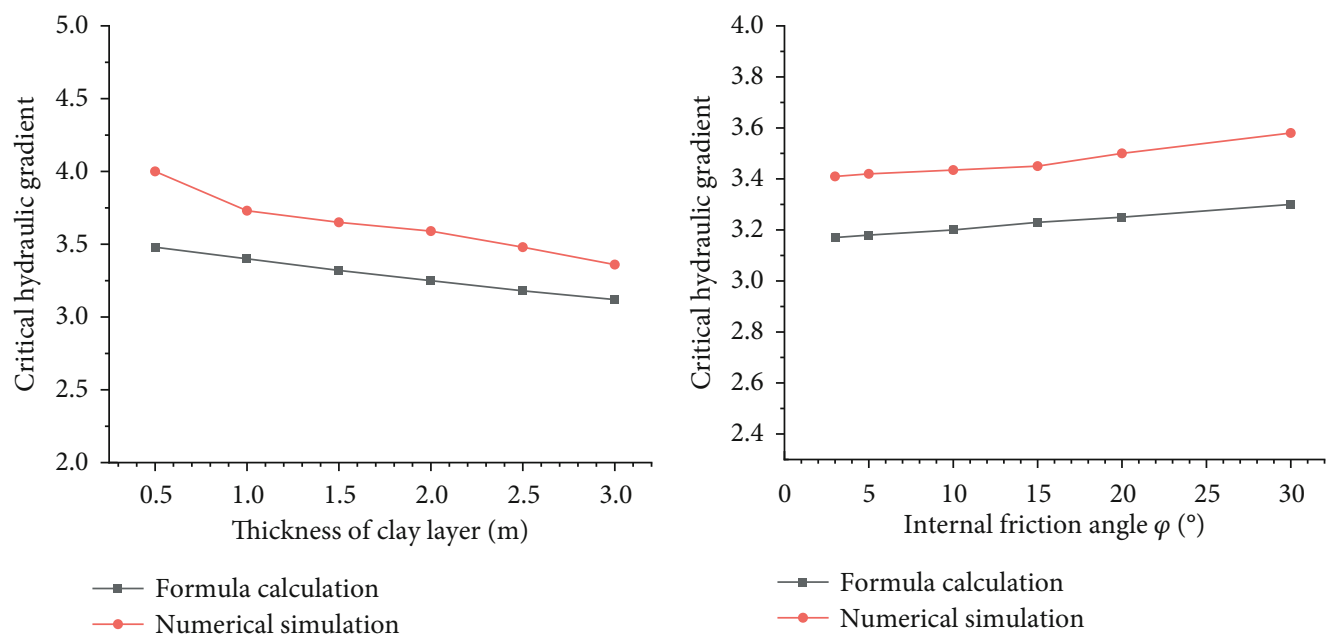

(a) $i_{\mathrm{cr}} \sim h$
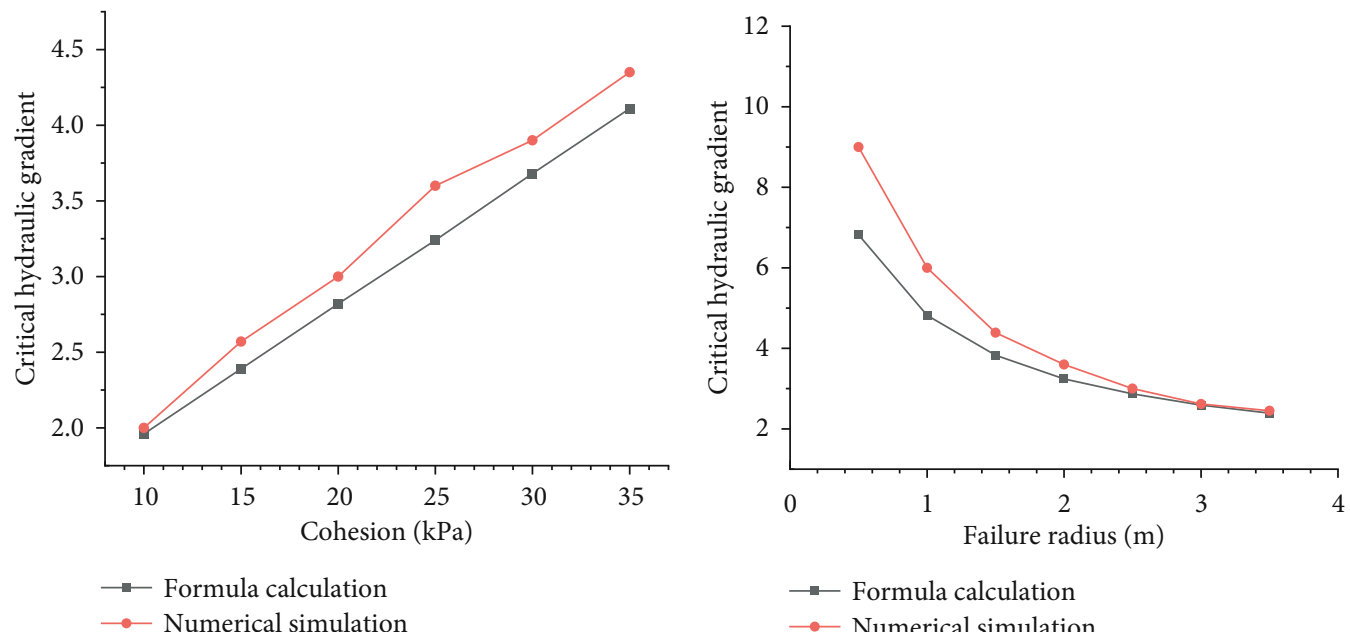

- Formula calculation

- Numerical simulation

(c) $i_{\mathrm{cr}} \sim c$

(d) $i_{\mathrm{cr}} \sim r$

Figure 9: Comparison between the formula solution and numerical simulation results. 


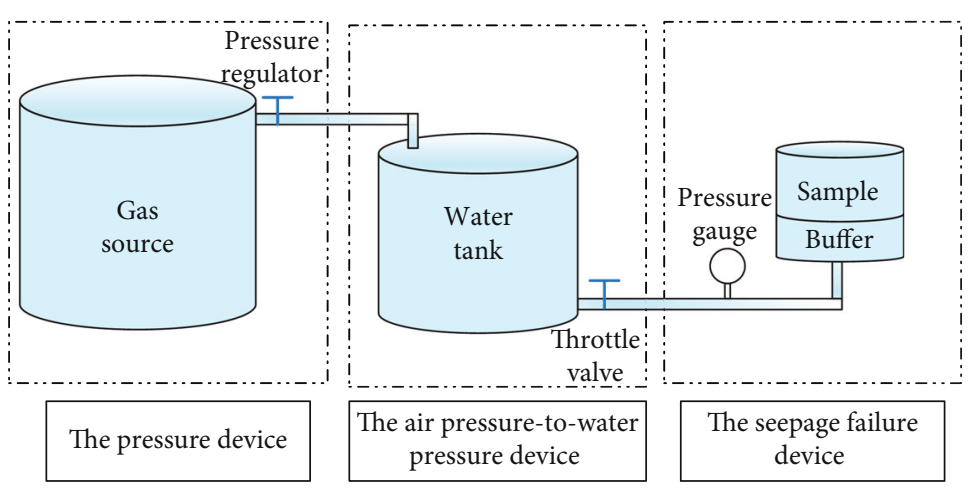

FIGURE 10: Schematic diagram of test facility.

numerical test results, this paper stipulates that the flow failure of clay layer occurs when the strain reaches $0.2 \sim 0.3 \%$. Take the $z-x$ section at $1 / 2$ length along the $y$-axis direction of the model, as shown in Figure 7(b). When seepage failure occurs in basic working conditions, the contour cloud map of strain, vertical displacement, and flow velocity at this section are shown in Figure 8.

Figures 9(a)-9(d) show the relation curves of "critical hydraulic gradient-clay layer thickness," "critical hydraulic gradient-internal friction angle," "critical hydraulic gradient cohesion," and "critical hydraulic gradient-failure radius", respectively. The following conclusions can be drawn from the analysis of them: (a) The change law of the two curves of "critical hydraulic slope-clay layer thickness" obtained by the formula calculation and numerical simulation is basically consistent, and the rule is that the critical hydraulic slope decreases with the increase of clay layer thickness. The maximum difference between the numerical simulation results and the formula results is about 7\%. (b) When the internal friction angle is used as a variable, the results of numerical simulation and formula calculation show that the critical hydraulic gradient is positively correlated with the internal friction angle, and the maximum difference between the two results is about $8 \%$. In general, the internal friction angle has little effect on the critical hydraulic gradient of cohesive soil foundation. When the internal friction angle changes from $3^{\circ}$ to $20^{\circ}$, the change rate of critical hydraulic gradient calculated by Eq. (16) is about $2.5 \%$, and the change rate of numerical simulation results is about $3.6 \%$; therefore, the influence of internal friction angle on critical hydraulic gradient can be ignored. (c) The "critical hydraulic gradient cohesion" curve obtained by numerical simulation is in good agreement with the corresponding calculation results of Eq. (16), which all show that the critical hydraulic gradient has a positive correlation with cohesion. The reason is that the greater the cohesion of soil is, the higher the shear strength of soil is, the greater the force between the soil particles that needs to be overcome to cause seepage failure, and the greater the critical hydraulic gradient of the cohesive soil is. (d) The law reflected by the two curves of "critical hydraulic gradientfailure radius" obtained by the formula calculation and numerical simulation is basically consistent. When the failure radius is less than the thickness of the clay layer, the critical hydraulic gradient increases rapidly with the decrease of

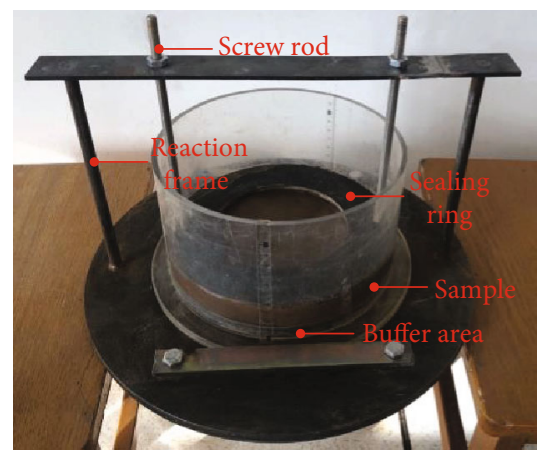

FIGURE 11: Seepage failure device.

the failure radius; on the contrary, when the failure radius is greater than the thickness of the clay layer, the critical hydraulic gradient decreases gradually with the increase of the failure radius.

In general, although there is a certain degree of error between the formula calculation results and the numerical experiment results, the results of the two are basically the same. The reason for the error may be that the failure shape of the weakened area of the clay layer is assumed to be a cylinder failure mode or an inverted frustum of a cone failure mode in the derivation of Eq. (16). However, the failure shape is not limited during the numerical experiment. Therefore, there is a certain error between the two calculation results.

After the above comparison, it can be considered that it is feasible to use Eq. (16) to calculate the critical hydraulic gradient of the cohesive soil foundation.

\section{Experiment Verification}

5.1. Experiment Equipment. The self-made test instrument is composed of the pressure device, air pressure-to-water pressure conversion device, and seepage failure device, as shown in Figure 10, whose main functions can not only control the thickness of the clay layer and the size of the seepage failure opening, but also make an application of controllable variable head pressure or constant head pressure to the cohesive soil samples.

The air pressure-to-water pressure conversion device with an air inlet at the top is connected with the gas source 
TABLE 2: Main parameters of soil sample.

\begin{tabular}{lcccccc}
\hline Soil type & Porosity $(n)$ & Dry density $\left(\mathrm{g} / \mathrm{cm}^{3}\right)$ & Water content $(\%)$ & $\mathrm{Cu}$ & Cohesion $(\mathrm{kPa})$ & Internal friction angle \\
\hline Sandy loam & 0.8 & 1.50 & 14.5 & 2.70 & 5.25 & $15.84^{\circ}$ \\
Loess & 0.6 & 1.70 & 16 & 2.71 & 20.5 & $24.01^{\circ}$ \\
\hline
\end{tabular}

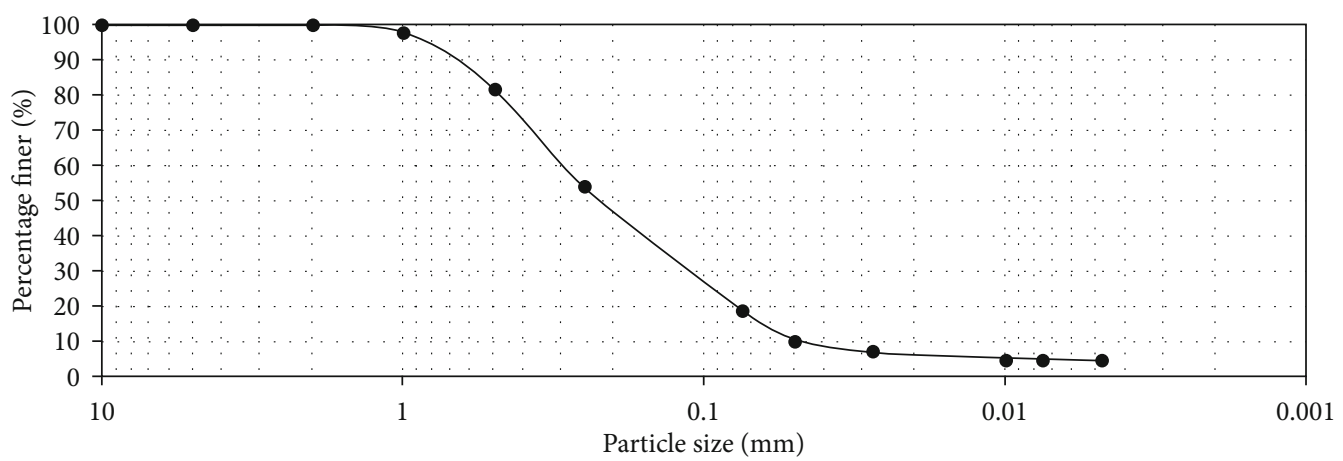

(a) Particle size distribution curve of sandy loam

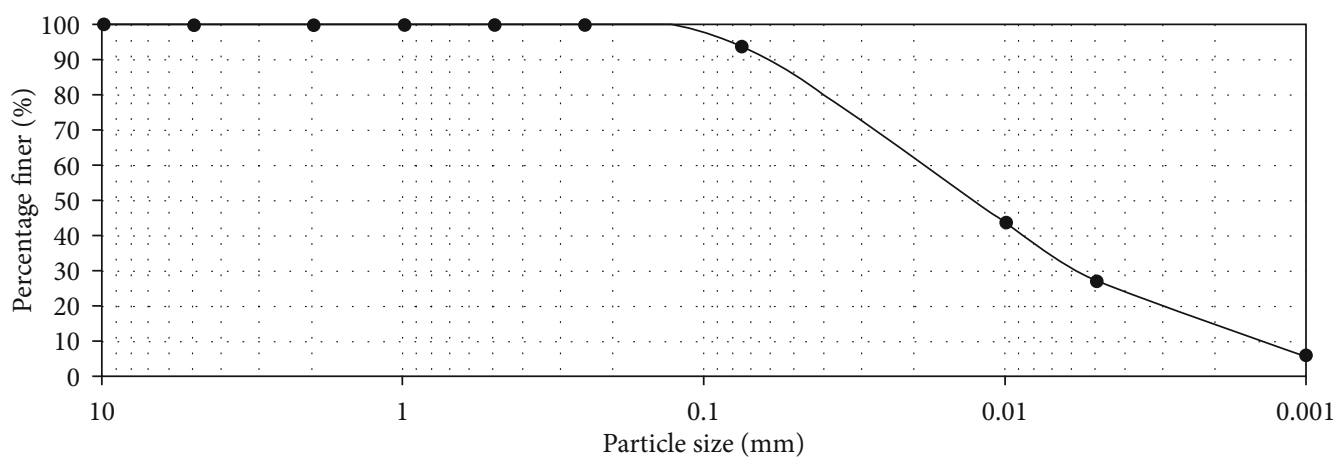

(b) Particle size distribution curve of loess

FIgUre 12: Particle size distribution curve of soil sample.

through the high-pressure pipe, so as to apply air pressure to the water tank. In addition, a water outlet at the device bottom is connected to the bottom of the seepage failure device through a high-pressure pipe, in order to apply water pressure to the bottom of the samples. Meanwhile, the flow velocity and water pressure measure are controlled by the throttle valve and pressure gauge, respectively.

The seepage failure device is set on the pedestal, shown in Figure 11. The test soil samples are fixed by the self-made reaction frame whose beam equips two screw rods, and the bottom of the screw rods can install the sealing ring with different inner diameters that can contact closely with the surface of the soil samples, which not only can change the exposed size of the soil samples but also prevent the concentrated leakage at the inside wall of the glass bucket. Moreover, it is necessary to note that pervious stone and filter paper must be placed at the bottom of the soil sample during the experiment so that the water pressure is applied evenly to the soil sample.

5.2. Experiment Plans. The previous research experiences show that apart from the physical properties of the soil, the thickness of the clay layer and the radius of the failure opening are great related to the critical hydraulic gradient of cohe-
TABLE 3: Soil sample size table.

\begin{tabular}{lccccc}
\hline $\begin{array}{l}\text { Sample } \\
\text { No. }\end{array}$ & $\begin{array}{c}\text { Radius } \\
(\mathrm{cm})\end{array}$ & $\begin{array}{c}\text { Height } \\
(\mathrm{cm})\end{array}$ & $\begin{array}{c}\text { Sample } \\
\text { No. }\end{array}$ & $\begin{array}{c}\text { Height } \\
(\mathrm{cm})\end{array}$ & $\begin{array}{c}\text { Radius } \\
(\mathrm{cm})\end{array}$ \\
\hline H1/S1 & 5 & 1 & HR1/SR1 & 2 & 1 \\
H2/S2 & 5 & 3 & HR2/SR2 & 2 & 2 \\
H3/S3 & 5 & 5 & HR1/SR3 & 2 & 4 \\
H4/S4 & 5 & 7.5 & HR1/SR4 & 2 & 8 \\
H5/S5 & 5 & 10 & HR5/SR5 & 2 & 10 \\
\hline
\end{tabular}

sive soil foundations. Therefore, this paper focuses on influences of clay layer thickness and failure radius on the critical hydraulic gradient. The soil samples are taken from the loess of Bin County and the sandy loam of The Yellow River beach of Yinchuan, both of which are remolded soil. The main parameters are shown in Table 2, and the particle size distribution is shown in Figure 12.

The loess soil samples with numbers as $\mathrm{H} 1, \mathrm{H} 2, \mathrm{H} 3, \mathrm{H} 4$, and $\mathrm{H} 5$ and the sandy loam soil samples with numbers as S1, S2, S3, S4, and S5 are, respectively, prepared for studying the influence of clay layer thickness on critical hydraulic gradient. Similarly, the loess soil samples with numbers as HR1, 


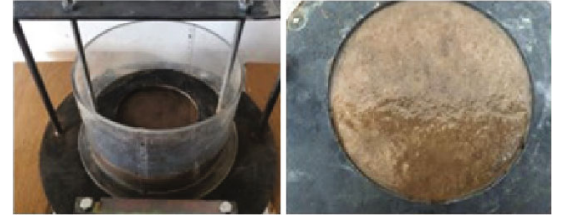

(a) The first stage

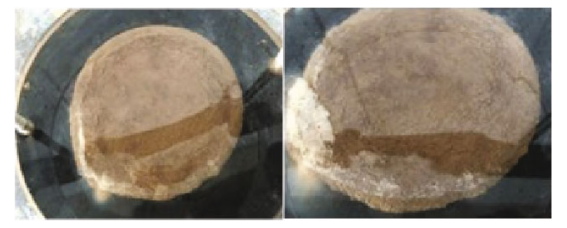

(c) The third stage

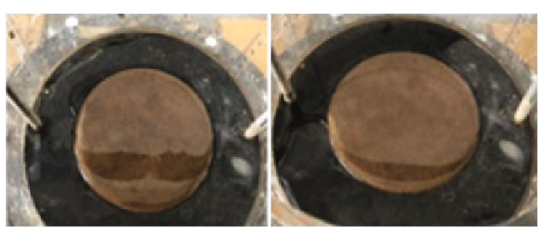

(b) The second stage

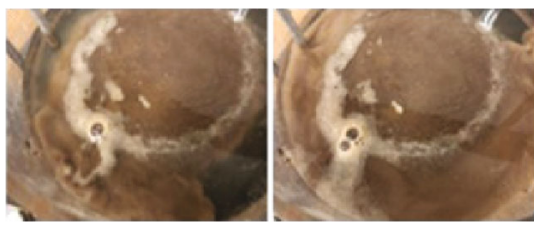

(d) The fourth stage

FIGURE 13: Diagram of seepage failure process of soil sample HR1/SR3.

HR2, HR3, HR4, and HR5 and the sandy loam soil samples with numbers as SR1, SR2, SR3, SR4, and SR5 are, respectively, prepared for studying the influence of failure radius on critical hydraulic gradient. The sample sizes are shown in Table 3.

5.3. Experiment Process. Before the test, keep the water pipe tightly connected to the gas source and water tank and not to the bottom of the seepage failure device temporarily, and the pipe mouth be open. Next, inject about $1200 \mathrm{~mL}$ water into the water tank and turn on the gas source, and the air pressure should be applied slowly to the tank by controlling the pressure regulating valve, and then, connect the pipe to the bottom of the seepage failure device when water overflows from the end of water pipe equipped with a pressure gauge. When the experiments are carrying out, the seepage failure process can be realized by step-by-step pressurization. The specific operation method is to apply a small water pressure to the soil sample at the beginning by adjusting the pressure regulating valve and observe the soil sample under the water pressure for 30 minutes continuously. If the seepage phenomenon changes continuously within 30 minutes, the observation time should be extended until the phenomenon becomes stable, and then, increase the water pressure $(0.002 \mathrm{MPa})$ to observe the next stage. It should be noted that when the critical point of osmotic failure is nearly reached, the pressure is applied step by step at the order of $0.0005 \mathrm{MPa}$. The characteristics of losing a large amount of soil particles and of increasing seepage water volume per unit time significantly and of having an apparent soil bulge occurrence can act as a criterion for estimating the seepage failure or not of the soil samples. The water pressure value when the seepage failure happen is converted into the height of water head $\Delta h$, and the critical hydraulic gradient is $i_{\text {cr }}=\Delta h / L$, where $L$ is the thickness of the soil samples.

5.4. Experimental Results. According to the experimental phenomena, the seepage failure of soil samples can be divided into the following four stages (see Figure 13): (a) There is a small amount of water slowly seeping out, no uplift occurrence at the top of the soil samples, and no seepage channel on the soil samples' side surface. (b) With the increase of
TABLE 4: Critical hydraulic gradient results of soil samples.

\begin{tabular}{lccccc}
\hline $\begin{array}{l}\text { Sample } \\
\text { codes }\end{array}$ & $\begin{array}{c}i_{\text {cr }} \text { /formula } \\
\text { solutions }\end{array}$ & $\begin{array}{c}i_{\text {cr }} \text { test } \\
\text { results }\end{array}$ & $\begin{array}{c}\text { Sample } \\
\text { codes }\end{array}$ & $\begin{array}{c}i_{\text {cr }} / \text { formula } \\
\text { solutions }\end{array}$ & $\begin{array}{c}i_{\text {cr }} \text { /test } \\
\text { results }\end{array}$ \\
\hline HR1 & 281.79 & 240 & H1 & 81.1 & 80 \\
HR2 & 170.35 & 150 & H2 & 74.56 & 73.33 \\
HR3 & 94.87 & 100 & H3 & 68.81 & 64 \\
HR4 & 65.87 & 60 & H4 & 62.60 & 58.67 \\
HR5 & 50.54 & 45 & H5 & 57.31 & 54 \\
SR1 & 77.87 & 70 & S1 & 21.70 & 20 \\
SR2 & 46.06 & 45 & S2 & 20.32 & 18.33 \\
SR3 & 25.55 & 22.5 & S3 & 19.08 & 16 \\
SR4 & 17.86 & 15 & S4 & 17.69 & 15.33 \\
SR5 & 13.84 & 12.5 & S5 & 16.48 & 14 \\
\hline
\end{tabular}

water pressure, the top of soil samples slightly rises, and the amount of clear water seepage increases gradually. (c) Cracks first appear on the upper surface of the soil samples along the inner edge of the iron ring, and the uplift phenomenon on the upper surface of soil continues to intensify, and at the same time, a little bit of soil particle suspension begins to occur on the upper surface of the soil samples. (d) With the progress of the seepage failure tests, the surface cracks of the soil samples gradually expand, and in the center of the uplift part of soil samples, cracks can be found and therefore can infer that there is a seepage channel in the sample interior so that it leads to an abrupt emergence of a large amount of soil particle suspension, which means that the soil samples fall into seepage failure. The seepage failure process of soil sample is shown in Figure 13.

The test and formula calculation results of different soil samples are shown in Table 4; in addition, the relation curves of "critical hydraulic gradient-failure radius" and "critical hydraulic slope-sample height" are, respectively, shown in Figure 14.

5.4.1. Influence of Failure Radius on Critical Hydraulic Gradient. The results show that the critical hydraulic gradient of cohesive soil foundation decreases with the increase of failure radius. The reason is that the larger the failure 


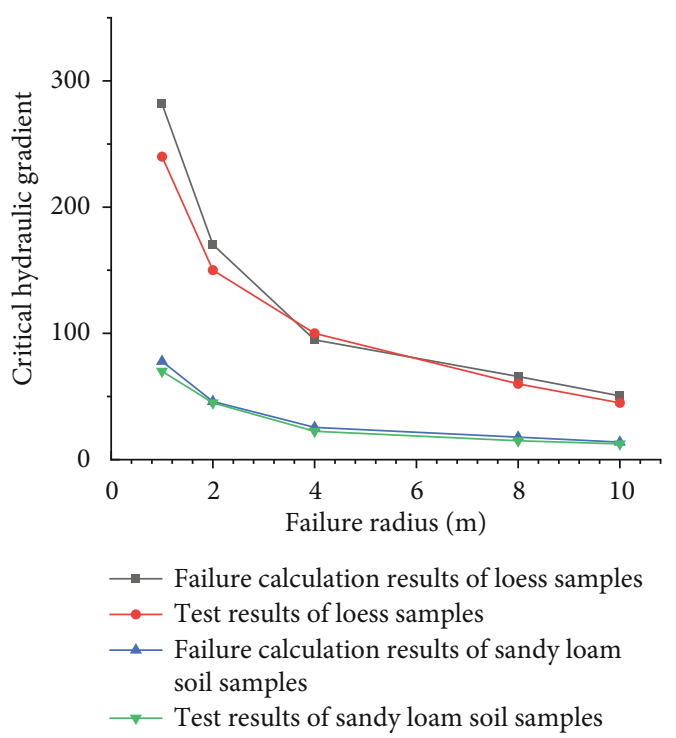

(a) The relation curve of "critical hydraulic gradient-failure radius"

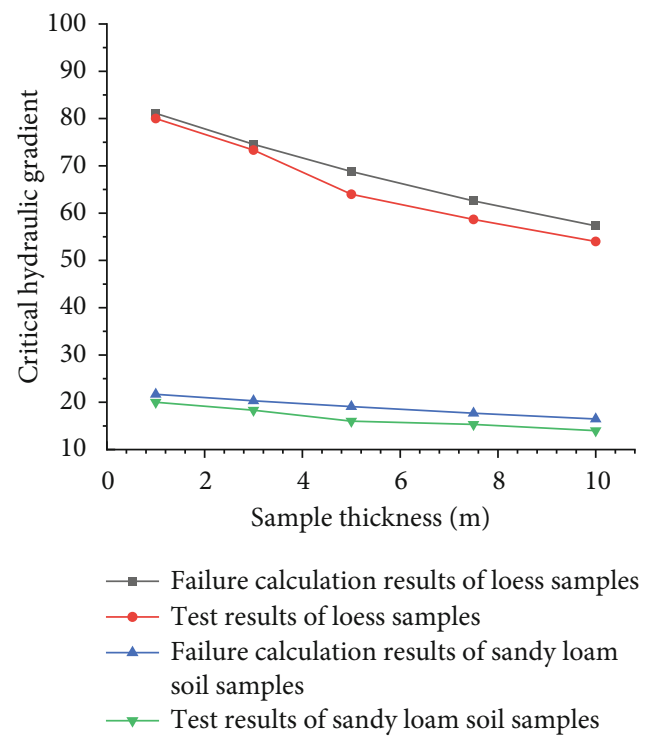

(b) The relation curve of "critical hydraulic gradient-sample thickness"

FIGURE 14: Comparison of formula solution and seepage test results.

TABLE 5: Results of experiments and calculation for critical hydraulic gradient.

\begin{tabular}{lcccccc}
\hline Soil type & $\begin{array}{c}\text { Dry density } \\
\left(\mathrm{g} / \mathrm{cm}^{3}\right)\end{array}$ & $\begin{array}{c}\text { Initial water } \\
\text { content }\end{array}$ & $\begin{array}{c}\text { Sample water } \\
\text { content }\end{array}$ & $\begin{array}{c}\text { Soil sample } \\
\text { volume }\end{array}$ & $\begin{array}{c}i_{\text {cr }} / \text { literature } \\
\text { test }\end{array}$ & $\begin{array}{c}i_{\text {cr }} / \text { formula } \\
\text { calculation }\end{array}$ \\
\hline Clay [31] & 1.70 & $5.1 \%$ & $20.1 \%$ & $120 \mathrm{~cm}^{3}$ & 110 & 119.96 \\
Silty clay [32] & 1.70 & $5.1 \%$ & $20.1 \%$ & $120 \mathrm{~cm}^{3}$ & 70 & 77.67 \\
Silty clay [32] & 1.61 & $22.5 \%$ & $20 \%$ & $120 \mathrm{~cm}^{3}$ & 45 & 49.17 \\
\hline
\end{tabular}

radius is, the smaller the constraint of the soil cohesion on the surrounding soil will be; therefore, the smaller the upward seepage force needed for the seepage failure and the smaller the critical hydraulic gradient will be. It is easy to see from Figure 14(a) that if the failure radius is constant, the critical hydraulic gradient of loess is always greater than that of sandy loam. When the corresponding failure radius increases from $1 \mathrm{~cm}$ to $4 \mathrm{~cm}$, for loess and sandy loam, the critical hydraulic gradient all drops greatly, decreasing by $62.3 \%$ and $17.4 \%$, respectively. As the failure radius is larger than $4 \mathrm{~cm}$, the decline trend of critical hydraulic gradient is relatively gentle. The reason may be that when the failure radius is equal to $4 \mathrm{~cm}$ in this tests, the seepage channel is easy to be formed inside the soil sample, which is conducive to the seepage failure of the soil sample. Moreover, the results of "critical hydraulic gradient-failure radius" obtained by seepage failure tests match highly to the corresponding calculation results of the new formula in this paper. The maximum difference value between the test results and the formula solutions is less than $16 \%$, whether the soil samples are loess or sandy loam.

\subsubsection{Influence of Soil Sample Thickness on Critical Hydraulic} Gradient. In analyzing Figure 14(b), it can be seen that when the soil sample thickness is constant, the critical hydraulic gradient of loess is always greater than that of sandy loam soil. The overall trend is that the critical hydraulic gradient of cohesive soil foundation decreases slowly with the increase of soil sample thickness, and when the thickness of soil samples increases from $1 \mathrm{~cm}$ to $10 \mathrm{~cm}$, the critical hydraulic gradient of loess soil and sandy loam soil decreases by $2.64 \%$ and $0.58 \%$, respectively. It is worth noting here that the thicker the clay layer, the decrease of the critical hydraulic gradient rather than the decrease of the critical damage head.

When the soil samples are loess, the maximum difference value between the critical hydraulic determined by the tests and the calculation results of the formula is less than $10 \%$. When the soil sample thickness is thin, the difference between the test results and the formula calculation results is greatly small, and the difference increases as the increase of soil sample thickness. The difference increases from $1.36 \%$ to about $7 \%$ when the soil sample thickness increases from $1 \mathrm{~cm}$ to $5 \mathrm{~cm}$. For sandy loam soil, this maximum difference value is less than $15 \%$, like the loess soil samples, in which the difference is smaller when the soil sample thickness is thinner. The reason for this may lie in the thicker the soil samples are, the more difficult to saturate; therefore, incomplete saturation phenomenon may exist, besides a small amount of soil is in aggregate form where distribute pores may also cause the internal stability of the entire soil to decrease, and the impermeability of fine particles cannot be better utilized [30]. 
5.5. Comparison of Formula Solution and Reference Test Results. In order to further verify the rationality of Eq. (16), the test data in references $[31,32]$ are taken as the original data, which are substituted into Eq. (16) for analysis and comparison. In reference [31], the internal friction angle of clay and silty clay is $20^{\circ}$ and $23^{\circ}$, respectively, and the cohesion is $22.5 \mathrm{kPa}$ and $15 \mathrm{kPa}$, respectively; in reference [32], the internal friction angle of silty clay is $22^{\circ}$ and the cohesion is $9.5 \mathrm{kPa}$, and the results are shown in Table 5 . It can be seen that the calculation results of the formula are close to the experimental results of references [31,32].

\section{Conclusion}

Based on the calculation method of critical hydraulic gradient of Terzaghi, a formula for calculating the critical hydraulic gradient of soil foundation considering the influence of shear strength of soil is established in this paper, which is validated with both numerical simulations and experimental tests. The conclusions are as follows:

(1) According to the equilibrium relationship among the upward seepage force, the downward effective gravity and the shear force of the cohesive soil foundation, the calculation formula of the critical hydraulic gradient of the cohesive soil foundation is derived

(2) The results obtained by numerical simulation are in good agreement with the corresponding calculation results of the new formula. In addition, the maximum difference value between the critical hydraulic gradient calculated by the formula and the seepage failure test results is about $16 \%$, which is sufficient to indicate that the formula is feasible

(3) The influence of the stress diffusion angle and the internal friction angle on the critical hydraulic gradient can be ignored when the internal friction angle does not exceed $10^{\circ}$

(4) The newly established formula can provide a theoretical basis for the mechanism analysis of dams, foundation pits, and other projects after destruction and contribute a reference basis to the design of dams and foundation pits, so as to reduce or avoid the occurrence of engineering safety accidents

\section{Data Availability}

Data supporting the results of this study can be obtained from the article.

\section{Conflicts of Interest}

The authors declare that they have no known competing financial interests or personal relationships that could have appeared to influence the work reported in this paper.

\section{Acknowledgments}

This paper was supported by the National Natural Science Foundation of China (Nos.: 51979225 and 51679199), the Ministry of Water Resources Public Welfare Industry Research Project (No.: 201501034-04), and the Shaanxi Key Laboratory of Science and Technology Innovation Project (No.: 2014SZS15-Z01).

\section{References}

[1] R. U. Naihua and N. Yunguang, Embankment Dam. Incidents and Safety of Large Dams, China Water Power Press, Beijing, 2001.

[2] M. A. O. Changxi, Seepage Computation Analysis \& Control, Water Resources and Electric Power Press, Beijing, 2002.

[3] C. Wu, J. Chu, S. Wu, and Y. Hong, "Wu S.etal. 3D characterization of the microbially induced carbonate precipitation within rock fracture and the resulted permeability reduction," Engineering Geology, vol. 249, pp. 23-30, 2019.

[4] C. Wu, J. Chu, S. Wu, L. Cheng, and L. A. van Paassen, "Microbially induced calcite precipitation along a circular flow channel under a constant flow condition," Acta Geotechnica, vol. 14, no. 3, pp. 673-683, 2019.

[5] Y. Xue, J. Liu, F. Dang, X. Liang, S. Wang, and Z. Ma, "Influence of $\mathrm{CH}_{4}$ adsorption diffusion and $\mathrm{CH}_{4}$-water two-phase flow on sealing efficiency of caprock in underground energy storage," Sustainable Energy Technologies and Assessments, vol. 42, article 100874, 2020.

[6] Y. Xue, P. G. Ranjith, F. Dang et al., "Analysis of deformation, permeability and energy evolution characteristics of coal mass around borehole after excavation," Natural Resources Research, vol. 29, no. 5, pp. 3159-3177, 2020.

[7] F. Zhang, T. Wang, F. Liu, M. Peng, J. Furtney, and L. Zhang, "Modeling of fluid-particle interaction by coupling the discrete element method with a dynamic fluid mesh: implications to suffusion in gap-graded soils," Computers and Geotechnics, vol. 124, article 103617, 2020.

[8] F. Zhang, M. Li, M. Peng, C. Chen, and L. Zhang, "Threedimensional DEM modeling of the stress-strain behavior for the gap-graded soils subjected to internal erosion," Acta Geotechnica, vol. 14, no. 2, pp. 487-503, 2019.

[9] M. An, F. Zhang, D. Elsworth, Z. Xu, Z. Chen, and L. Zhang, "Friction of Longmaxi shale gouges and implications for seismicity during hydraulic fracturing," Journal of Geophysical ResearchSolid Earth, vol. 125, no. 8, article e2020JB019885, 2020.

[10] F. Zhang, B. Damjanac, and S. Maxwell, "B. Damjanac, S. Maxwell. Investigating hydraulic fracturing complexity in naturally fractured rock masses using fully coupled multiscale numerical modeling," Rock Mechanics and Rock Engineering, vol. 52, no. 12, pp. 5137-5160, 2019.

[11] T. Rabczuk and T. Belytschko, "Cracking particles: a simplified meshfree method for arbitrary evolving cracks," International Journal for Numerical Methods in Engineering, vol. 61, no. 13, pp. 2316-2343, 2004.

[12] H. Ren, X. Zhuang, and T. Rabczuk, "Dual-horizon peridynamics: a stable solution to varying horizons," Computer Methods in Applied Mechanics and Engineering, vol. 318, pp. 762-782, 2017.

[13] K. V. Terzaghi, "Der grundbruch an stauwerken und seine verhuetung," Wasserkraft, vol. 17, no. 24, pp. 445-449, 1922. 
[14] J. Israr and B. Indraratna, "Study of critical hydraulic gradients for seepage-induced failures in granular soils," Journal of Geotechnical and Geoenvironmental Engineering, vol. 145, no. 7, article 04019025, 2019.

[15] M. LI and R. J. Fannin, "A theoretical envelope for internal instability of cohesion less soil," Geotechnique, vol. 62, no. 1, pp. 77-80, 2012.

[16] M. Wang, Y. Jiang, L. Yu, Y. Dong, and R. Duan, "Calculation method of starting critical hydraulic slope of fine particles in sandy soil," Rock and Soil Mechanics, vol. 41, no. 8, pp. 2515-2524, 2010.

[17] F. Jiang, "Discussion on formula derivation and test of critical hydraulic condition of cohesive soil," Chinese Journal of Underground Space and Engineering, vol. 13, no. 6, pp. 14721476, 2017.

[18] M. Wu and G. Gao, "Research on prediction method of critical gradient for piping of sand and gravel soils," Rock and Soil Mechanics, vol. 40, no. 3, pp. 1-10, 2019.

[19] Y. Luo, B. Su, J. Sheng, and M. Zhan, "New understanding of piping mechanism," Journal of Geotechnical Engineering, vol. 33, no. 12, pp. 1895-1902, 2011.

[20] Y. Luo, Q. Wu, M. Zhan, and J. Sheng, "Experimental study on critical piping gradient of suspended cutoff wall gravel foundation considering stress state," Rock and Soil Mechanics, vol. 33, no. S1, pp. 73-78, 2012.

[21] Y. Tang, W. Shi, and X. Zhang, "The experiments study and theoretical analyses on piping and flow soil," Shanghai Land \& Resources, vol. 1, pp. 25-31, 2003.

[22] Y. Liang, T. C. J. Yeh, Y. Zha, J. Wang, M. Liu, and Y. Hao, “T C J YEH, Y Y ZHA..Onset of suffusion in gap-graded soils under upward seepage(article)," Soils and Foundations, vol. 57, no. 5, pp. 849-860, 2017.

[23] J. Yang, Y. Cai, and Y. Zhu, "Experimental study on contact soil flow considering stress condition," Yangtze River, vol. 41, no. 7, pp. 79-81, 2010.

[24] F. Dang, H. Liu, X. Wang, H. Xue, and Z. Ma, "Emperimental of study on the relevance between stress state and seepage failure of Sandy-gravel soil," Chinese Journal of Rock Mechanics and Engineering, vol. 34, no. 9, pp. 1909-1917, 2015.

[25] Z. Jiang, W. Wang, S. Feng, and H. Zhong, "Empirical formulas of permeability of clay based on effective pore ratio," Journal of Hydraulic Engineering, vol. 44, no. 12, pp. 1498-1505, 2013.

[26] K. Zhang and S. Liu, Soil Mechanics(The third edition), China Building Industry Press, Beijing, 2010.

[27] X. Dong, J. Ma, Z. Hu, J. Li, and L. Xu, "Study on foundation stress dispersion effect in saturated sand based on centrifugal model test," Railway Standard Design, vol. 62, no. 1, pp. 8488, 2018.

[28] Y. Mai, "Earth pressure of saturated soft clay," Port \& Waterway Engineering, vol. 320, no. 9, pp. 3-6, 2000.

[29] X. Zhang, Q. Zhang, and Q. Gao, "Development and application of geotechnical direct tension test devices," Chinese Journal of Geotechnical Engineering, vol. 36, no. 7, pp. 13091315, 2014.

[30] M. Zhou, Study on Critical Hydraulic Slope of Fluid Soil Failure on Cohesive Soil, Xi 'an University of Technology, 2020.

[31] L. Jianguo, Seepage Failure Test and Numerical Simulation of Cohesive Soil, Hefei University of Technology, 2015.

[32] Q. He, Exprimental Study on Seepage Failure and Long-Term Seepage Degradation of Clay, Hefei University of Technology, 2017. 